\title{
Effect of a Misidentified Centre of a Type ASG Material Measure on the Determined Topographic Spatial Resolution of an Optical Point Sensor
}

\author{
Janik Schaude *(D), Andreas Christian Gröschl and Tino Hausotte (D)
}

check for updates

Citation: Schaude, J.; Gröschl, A. C.; Hausotte, T. Effect of a Misidentified Centre of a Type ASG Material

Measure on the Determined

Topographic Spatial Resolution of an Optical Point Sensor. Metrology 2022,

2, 19-32. https://doi.org/

10.3390/metrology2010002

Academic Editor: Han Haitjema

Received: 13 October 2021

Accepted: 21 December 2021

Published: 5 January 2022

Publisher's Note: MDPI stays neutral with regard to jurisdictional claims in published maps and institutional affiliations.

Copyright: (c) 2022 by the authors. Licensee MDPI, Basel, Switzerland This article is an open access article distributed under the terms and conditions of the Creative Commons Attribution (CC BY) license (https:// creativecommons.org/licenses/by/ $4.0 /)$
Institute of Manufacturing Metrology, Friedrich-Alexander-Universität Erlangen-Nürnberg (FAU), Nägelsbachstr. 25, 91052 Erlangen, Germany; andreas.groeschl@fmt.fau.de (A.C.G.); tino.hausotte@fau.de (T.H.) * Correspondence: janik.schaude@fmt.fau.de

\begin{abstract}
The article presents the determination of the topographic spatial resolution of an optical point sensor. It is quantified by the lateral period limit $D_{\text {LIM }}$ measured on a type ASG material measure, also called (topographic) Siemens star, with a confocal sensor following both a radial measurement and evaluation, as proposed by ISO 25178-70, and the measurement and subsequent evaluation of two line scans, proposed by the NPL Good Practice Guide. As will be shown, for the latter, an only slightly misidentified target centre of the Siemens star leads to quite significant errors of the determined $D_{\text {LIM }}$. Remarkably, a misidentified target centre does not necessarily result in an overestimation of $D_{\mathrm{LIM}}$, but lower values might also be obtained. Therefore, a modified Good Practice Guide is proposed to determine $D_{\text {LIM }}$ more accurately, as it includes a thorough determination of the centre of the Siemens star as well. While the measurement and evaluation effort is increased slightly compared to the NPL Good Practice Guide, it is still much faster than a complete radial measurement and evaluation.
\end{abstract}

Keywords: surface metrology; topographic spatial resolution; lateral period limit; type ASG material measure; Siemens star; confocal sensor; nano measuring machine

\section{Introduction and Literature Review}

Surface texture determines the functional behaviour of a manufactured component and is therefore crucial in many different areas such as electronics, optics, medicine, information technology, or consumables [1-3]. As a result, surface metrology is an essential part of manufacturing metrology extensively dealt with within the ISO 25178 standards [4,5]. In the era of globalization and interchangeability, accurate and internationally comparable measurement results are indispensable [6]. Metrological comparability is ensured by the metrological traceability of the measurement result, which goes along with a statement about the measurement uncertainty $[7,8]$. The stylus method has been used for over 100 years in surface metrology [9], and due to the well understood interaction between the probe and the surface [10], it still serves as reference method for traceable surface measurements in different national metrology institutes [11-13]. Furthermore, atomic force microscopy (AFM, [14]) under tightly controlled environmental conditions and in ultrahigh vacuum enables a resolution down to the atomic scale [15,16], while metrological AFMs [17] ensure the traceability of the measurement results. Nevertheless, the measurement of soft surfaces by tactile methods is problematic due to the elastic or even plastic deformation of the workpiece caused by the applied probing force [18]. Not only are such issues irrelevant for optical methods, but the non-contact nature of probing also allows a measurement speed unprecedented by tactile methods [19]. Optical methods are therefore especially suited for in situ surface metrology [20]. The main benefit of in situ metrology is the more economical and also resource-efficient production due to the possibility to realize a very short quality control loop [21]. As process changes, e.g., alterations of the machine tool, influence surface 
texture, the latter is an indicator of the characteristics of the manufacturing process and thus is also suited to control processes for which surface texture itself actually is not the crucial parameter [22].

Nonetheless, a main issue about optical methods is their lack of traceability, and therefore comparison measurements, including tactile methods, as well as comparisons limited to different optical instruments, frequently reveal significant deviations of the reported results [23-31]. An explanation of the deviations between the optical and the tactile methods might be that the latter probe the mechanical surface, whereas optical methods probe the electromagnetic surface [32]. However, a more important issue might be the disregard of the metrological characteristics, especially the bandwidth, of the instruments involved within the comparisons [33], since there are also examples where measurement results taken with different instruments, both tactile and optical, do not differ significantly [34,35]. Hence, the understanding of the limitations of a measuring instrument is of prime importance, and it is necessary to choose an appropriate instrument for a given surface to be measured [33]. A comprehensive review about the calibration and verification of areal surface texture measuring instruments is given in [36].

ISO 25178-600 specifies seven metrological characteristics of an instrument: amplification coefficient, linearity deviation, flatness deviation, measurement noise, topographic spatial resolution, $x-y$ mapping deviations, and topography fidelity [37]. The scope of this paper is limited to the topographic spatial resolution $W_{R}$, which is defined as "the ability of a surface topography measuring instrument to distinguish closely spaced surface features" [37]. The standard does not specify how to quantify $W_{R}$. The most common in practice is the Rayleigh criterion [38] or the Sparrow criterion [39], which simply take the wavelength of light and the numerical aperture of the objective into account. Nevertheless, these criteria are rather the minimum values of $W_{R}$, and other influences might deteriorate $W_{\mathrm{R}}$ in practice [40]. Other approaches thus use, for instance, the instrument transfer function [41]. However, the applicability of this approach is limited [36]. An alternative possibility is the determination of the lateral period limit $D_{\text {LIM }}$, defined as "the spatial period of a sinusoidal profile at which the height response of an instrument falls to 50\%" [37].

Following this definition, artefacts with sinusoidal structures and discrete spatial wavelengths, called chirp calibration standards, with a uniform amplitude [42] or a varying amplitude [43] might be used to determine $D_{\text {LIM }}$. For an aperiodic spatial frequency standard, the discrete spatial wavelengths are superimposed, and the data evaluation contains a Fourier transformation to separate the discrete spatial wavelengths and the corresponding transferred amplitude of the measuring instrument [44,45]. Also known is the application of a one-dimensional rectangular grating with varying pitches [46]. Nevertheless, all the standards mentioned so far only provide a finite number of spatial wavelengths and therefore may be unsuitable to characterize a particular optical system [47].

As an alternative, a star-like arrangement of grooves (type ASG according to ISO 2517870 [48]), also called (topographic) Siemens star, which provides a continuous spectrum of spatial wavelengths, might be used to determine $D_{\text {LIM }}$ of an optical system [49]. The standard proposes a radial measurement and evaluation of the star's height to determine $D_{\text {LIM. }}$. Nevertheless, this procedure necessitates the measurement of the complete star, which is quite time consuming when a point sensor is applied. Furthermore, the accurate determination of the centre of the Siemens star is not a trivial task since it is actually defined by the edges of the grooves that are not measurable with most optical systems because of the limited angle of acceptance of the microscope objective. In [50], the centre is determined automatically by the application of a Radon transformation. In [51], a feature-recognition method and a variance-judgment method were shown to determine the star's centre. Instead of measuring the complete star, in [52], a faster measurement method especially suited for point sensors is demonstrated. It only measures and evaluates two lines taken at a groove and the adjacent top level, hereafter called the procedure following the NPL Good 
Practice Guide [53]. Of course, the evaluation method of this procedure is still applicable if the complete star has been measured.

In [54], the significant influence of a misidentified centre on the determined $D_{\text {LIM }}$ following the radial measurement and evaluation was proved. However, there is also a significant impact of the profile extraction on the determined $D_{\text {LIM }}$ when following the NPL Good Practice Guide [55]. In this paper, the effect of a misidentified centre on the determined $D_{\text {LIM }}$ of a confocal microscope is evaluated when following the NPL Good Practice Guide in Section 5.3. Based on this, in Section 5.4, a modified Good Practice Guide is proposed to determine $D_{\text {LIM }}$ more accurately. In Section $4, D_{\text {LIM }}$ is determined following the radial approach. The paper starts with an introduction of the setup of the sensor system in Section 2 and the determination of the workpiece coordinate system (WCS) in Section 3.

\section{Setup}

The confocal microscope, patented by Minsky in 1957 [56], offers a resolution superior to conventional microscopy, which was first shown theoretically [57] and shortly thereafter empirically [58]. Particularly impressive is the comparison of confocal and convetional microscopy on biological specimens [59], but the confocal microscope soon became also a tool of dimensional metrology [60] and is nowadays described in ISO 25178-607 [61]. Nevertheless, as is usual for optical instruments, the improvement of the resolution came along with a reduction in the field of view [62], which becomes one single point of diffractionlimited size in the case of confocal microscopy. To measure a topography, it is therefore necessary to move the specimen relative to the sensor both axially and laterally. For each lateral position, the surface height is determined by finding the maximum signal of the axial response [63]. Although there are beam scanning methods that omit the necessity to mechanically move the specimen laterally, e.g., by the application of a Nipkow disk [64] or movable mirrors $[65,66]$, for the investigations presented within this paper, we applied a setup operated in stage-scanning mode to demonstrate the determination of $D_{\text {LIM }}$ of an optical point sensor with a Siemens star.

The setup consisted of a fibre-coupled confocal sensor firstly described in [67] and in its latest design, as it was applied for the investigations shown within this paper, in [68]. A thorough description of the sensor, including the theory of the signal formation based on general works on fibre-coupled confocal sensors of Gu et al. [69], may be found in [70]. Thus, the setup will only be briefly summarized here.

The main parts of the confocal sensor, which is shown schematically in Figure 1, were a helium-neon laser (1) with a wavelength of about $633 \mathrm{~nm}$ and a pin-photodetector (2), which were coupled to a narrowband single-mode fibre coupler with an integrated beam splitter with a splitting ratio of 50:50 (6) by a focusing lens (4) and a collimation lens (5). An optical isolator (3) prevents light reflected by the surface from disturbing the laser and therefore causing increased variations in the laser output power. A fibreport with an aspheric lens (7) collimated the laser light, and an infinity-corrected $100 \times$ microscope objective with an extended long working distance of $4.5 \mathrm{~mm}$ and a numerical aperture of 0.8 (8) focused the beam on the measuring object (9). The setup was supplemented with an illumination and camera system for the visual location and observation of the measuring object (not shown in the figure).

The sensor was integrated into a nano measuring machine (NMM-1) [71,72] with a range of motion of $25 \mathrm{~mm} \times 25 \mathrm{~mm} \times 5 \mathrm{~mm}$, operated within a thermostating housing with a long-term temperature stability of $17 \mathrm{mK}$ [73]. The NMM-1 fulfils the Abbe comparator principle [74] in all three coordinate axes by keeping the measuring system (three perpendicular homodyne Michelson interferometers fed by stabilized helium-neon lasers with a resolution of less than $0.1 \mathrm{~nm}$ each) fixed and moving the measuring object. The measuring object was placed on a corner mirror, which defines the coordinate system and provides the three orthogonal measuring mirrors for the interferometers of the NMM-1. The focal point of the confocal sensor was approximately located at the intersection of the interferometer beams and kept at this position permanently. Furthermore, the additional angle sensors 
and the angle control of the corner mirror about the $x$-and $y$-axes of the NMM- 1 reduce the angular deviations during movement and thus any first-order deviations that arise. The measuring object was a type ASG material measure with a radius $r$ of $70 \mu \mathrm{m}$ and a nominal step height of $200 \mathrm{~nm}$ and 18 grooves of the NPL Bento Box [75]. The control of the NMM-1 and the evaluation of the data were conducted with MATLAB.

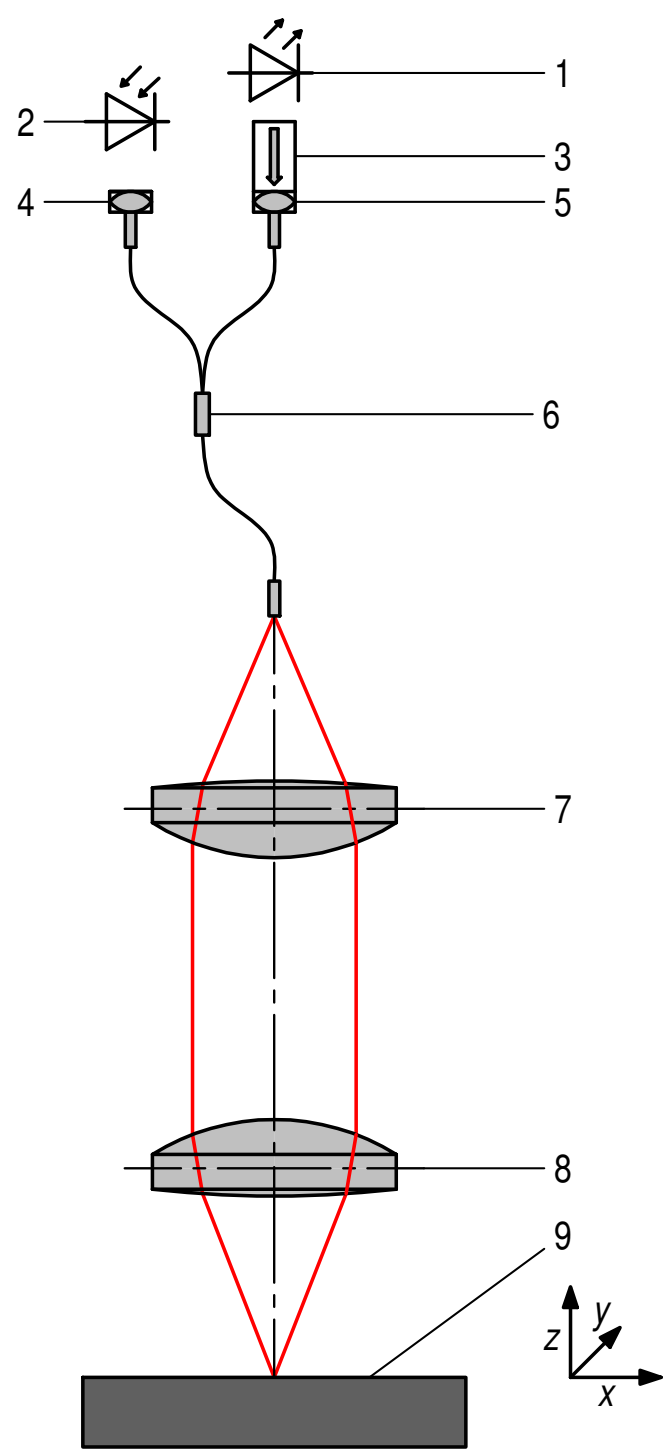

Figure 1. Schematic of the sensor: 1, laser; 2 , pin photodetector; 3 , optical isolator; 4 , focusing lens; 5 , collimation lens; 6 , fibre coupler; 7 , collimation lens; 8 , microscope objective; 9 , measuring object.

\section{Determination of the Workpiece Coordinate System}

Aided by the camera system, 18 points just outside the grooves of the Siemens star and its centre were roughly located manually (cf. Figure 2, red circles). At each point, an axial probing was conducted by sampling the values of the NMM- 1 interferometers and the signal of the photodetector $V_{\text {in }}$. Although the axial response of a confocal sensor on a plane surface is a sinc ${ }^{2}$-function [76], it is common to fit a Gaussian curve to the full axial response to determine the surface height with a high accuracy [63]. Thus, the surface height $z_{M}$ was determined by Gaussian curve fitting to the full axial response. To these 18 surface points a plane has been fitted following the least squares method. This plane defines the $x y$-plane of the WCS. Furthermore, from each surface point, a probing was conducted in the direction of the roughly determined centre of the Siemens Star. The edge of the Siemens star was determined, searching the location of the minimum value of $V_{\text {in }}$ as 
is shown in Figure 3. As it is problematic to measure high slopes with optical systems [77] and the measurement of edges might lead to great errors, such as batwing-effects [78], it is beneficial to use the unprocessed signal $V_{\text {in }}$ instead of $z_{\mathrm{M}}$ to determine an edge's position. To all determined positions of the edges, or rather their orthographic projection on the $x y$-plane of the WCS, a circle was fitted to determine the centre of the Siemens star, which is the origin of the WCS as well. The determined positions of the edges are also shown as red crosses in Figure 2.

For the subsequent areal measurements of the Siemens star, lateral scans were conducted at different heights. Only in postprocessing was the axial response at each lateral point retrieved to determine $z_{\mathrm{M}}$ by Gaussian curve fitting. It is well known that a decreased amplitude of the axial response may lead to less reliable data points [79]. Thus, all measured points were rejected for which the amplitude of the fitted Gaussian curve was below a certain threshold. The threshold was 50\% of the amplitude of the fitted Gaussian curve of the axial response on a plane area near the Siemens star. This filter already blocks edge effects, similar to batwings in coherence scanning interferometry [78] to some extent [80]. An axial range of $4 \mu \mathrm{m}$ was covered by the lateral scans with a step between two adjacent heights of $50 \mathrm{~nm}$. The lateral scans were centred around $z_{\mathrm{WCS}}=0$.
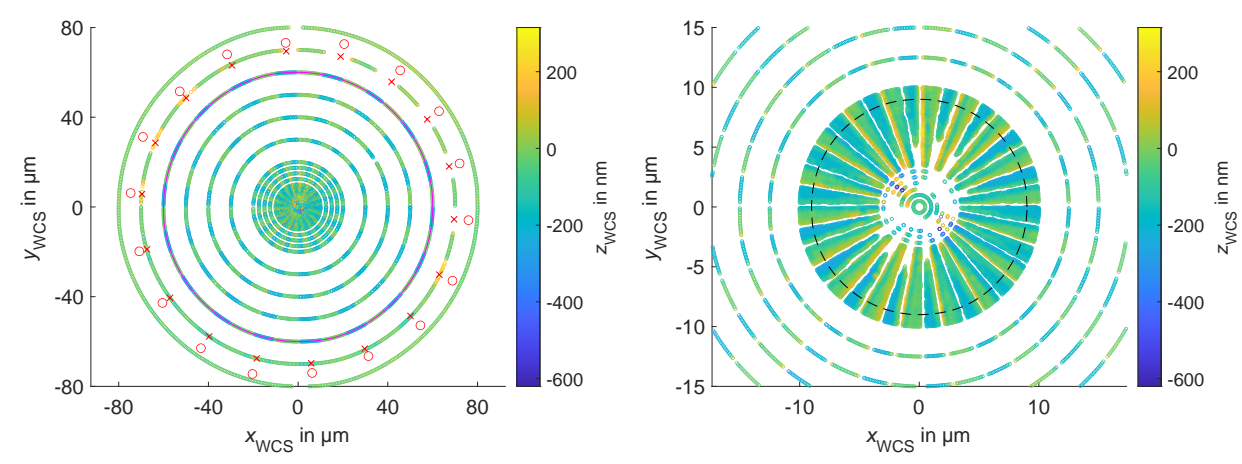

Figure 2. Whole Siemens star and the cut through $r=60 \mu \mathrm{m}$ (left) and its centre in more detail with the cut through $r=9 \mu \mathrm{m}$ (right). The cuts are shown in Figure 4. Shown also are the manually located positions just outside the grooves (red circles) and the determined edges (red crosses).

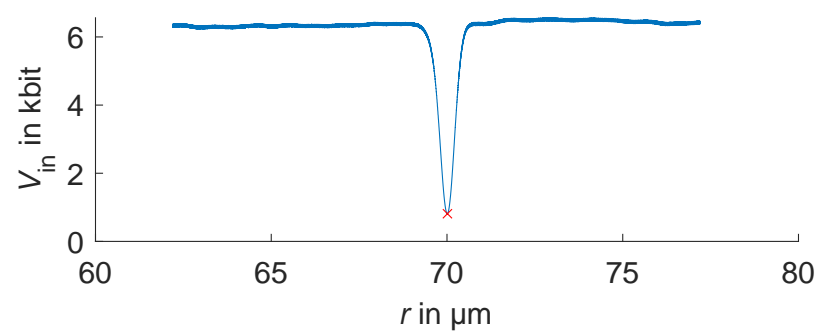

Figure 3. Lateral probing from just outside the Siemens star in the direction of its centre. Marked as a red cross is the determined location of the edge of the Siemens star.
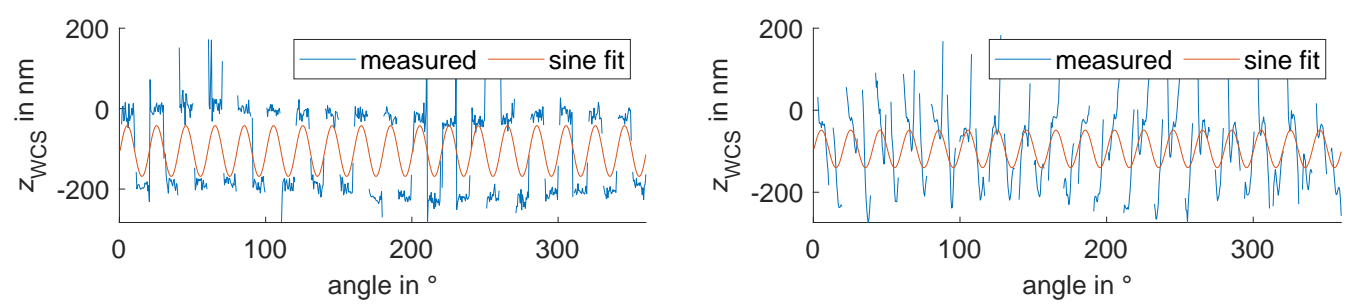

Figure 4. Radial cuts at $r=60 \mu \mathrm{m}$ (left) and $r=9 \mu \mathrm{m}$ (right). 


\section{Radial Measurement and Evaluation of $D_{\text {LIM }}$}

To begin with, $D_{\text {LIM }}$ is determined following an radial measurement and evaluation of the amplitude. The amplitude $a$ of each radial cut is determined by

$$
a=\sqrt{X^{2}+Y^{2}}
$$

where $X$ and $Y$ are determined by a Fourier series approximation with

$$
\begin{gathered}
X=\frac{1}{n} \cdot \sum_{i=1}^{n} z_{\mathrm{WCS}, i} \cdot \sin \left(2 \pi \cdot \frac{18 \cdot i}{n}\right) \text { and } \\
Y=\frac{1}{n} \cdot \sum_{i=1}^{n} z_{\mathrm{WCS}, i} \cdot \cos \left(2 \pi \cdot \frac{18 \cdot i}{n}\right),
\end{gathered}
$$

with $n$ denoting the number of data points of a cut and $i=1, \ldots, n$. Furthermore, the phase angle $\phi$ is determined by

$$
\phi=\operatorname{atan} 2(Y / X) .
$$

Figure 4 shows the radial cuts at $r=60 \mu \mathrm{m}$ and $r=9 \mu \mathrm{m}$. The sine fit is calculated by

$$
z_{i}=a \cdot \sin \left(2 \pi \cdot \frac{18 \cdot i}{n}+\phi\right) .
$$

In Figure $5, a$ and $\phi$ of each radial cut are shown over $r$. The amplitude, unaffected by the lateral resolution of the optical system, $a_{0}$, is calculated as mean of the amplitudes for the three highest radii (dashed red line). The radius for which $a$ falls to $50 \%$ of $a_{0}$ (dashed green line) is $r_{\text {LIM }}$. To determine $r_{\text {LIM }}$, the function $r(a)$ is calculated as linear polynomial with the data points, for which $a$ is below $50 \%$ of $a_{0}$ for the first time (for a decreasing $r$ ) and its eight neighbour data points. The calculated function $r(a)$ is shown as dashed magenta line and is used to calculate $r_{\text {LIM }}$ by

$$
r_{\text {LIM }}=r\left(0.5 \cdot a_{0}\right),
$$

which is $6.753 \mu \mathrm{m}$, and thus $D_{\mathrm{LIM}}=2.36 \mu \mathrm{m}$, calculated by

$$
D_{\text {LIM }}=\frac{2 \pi \cdot r_{\text {LIM }}}{18} \text {. }
$$

Note the peak of $a$ for $r \approx 2 \mu \mathrm{m}$. According to [54], this might by an artefact of a misidentified target centre.

This procedure is used to determine $r_{\text {LIM }}$ and $D_{\text {LIM }}$ throughout the remainder of the paper. Nevertheless, it should be noted that this is already an alteration of the NPL Good Practice Guide, because the latter calculates $a_{0}$ just as the maximum value of $a$ [53]. Nevertheless, as especially confocal systems tend to show an increased $a$ just before the drop [53] (p. 42), we rather propose calculating $a_{0}$ for a $r$ that is unaffected by the limited lateral resolution of the sensor. 

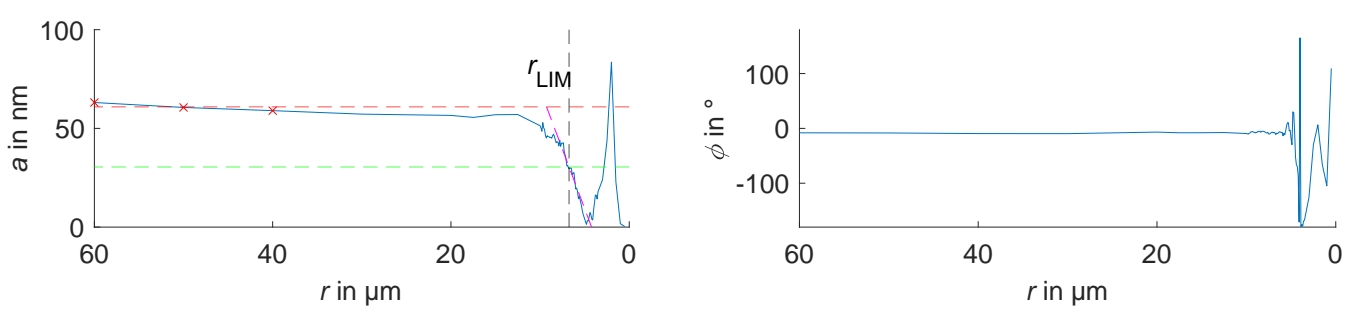

Figure 5. $a$ and $\phi$ over $r$. The dashed red line indicates the $a$ unaffected by the lateral resolution of the optical system, $a_{0}$, calculated as mean of the amplitudes for the three highest radii (red crosses), and the green dashed line is $50 \%$ of $a_{0}$. The polynomial $r(a)$ is shown as magenta dashed line and $r_{\text {LIM }}$ as dashed black line.

\section{Measurement and Evaluation of $D_{\text {LIM }}$ according to the NPL Good Practice Guide}

In this section, $D_{\text {LIM }}$ is evaluated according to the NPL Good Practice Guide. In the first part of this section, the evaluation is conducted with the areal measurement data of the complete star. In comparison, in the second part of this section, not only the evaluation but also the measurement is conducted according to the NPL Good Practice Guide. Thus, only two line scans are conducted instead of a complete radial measurement of the Siemens star.

\subsection{Evaluation of the Areal Measurement according to the NPL Good Practice Guide}

Following the NPL Good Practice Guide, two lines are taken from the radially measured data: one line through the middle of a groove, $z_{\mathrm{WCS}, 1}$, and one through the middle of the adjacent top level, $z_{\mathrm{WCS}, \mathrm{h}}$, as depicted in Figure 6 . The phase angle to go through the middle was $\left(\phi+90^{\circ}\right) / 18$, with the $\phi$ of the radial cut at $r=60 \mu \mathrm{m}$ calculated according to Equation (4). As shown in Figure 5, right, $\phi$ is very stable for the radii or rather the wavelengths $\lambda=2 \pi \cdot r / 18$ that are well over $D_{\mathrm{LIM}}$, and therefore a different $r$ might also have been chosen.

The evaluation of $D_{\mathrm{LIM}}$ is conducted with the difference of $z_{\mathrm{WCS}, 1}$ and $z_{\mathrm{WCS}, \mathrm{h}}, \Delta z$, as is depicted in Figure 7. $a_{0}$ is calculated as mean of $\Delta z$ of the utmost radii, and the cut-off at each side is calculated with a polynomial regression (similar to the procedure described in Section 4). The distance between both cut-offs, $2 r_{\mathrm{LIM}}$, is $14.688 \mu \mathrm{m}$, and therefore $D_{\mathrm{LIM}}=14.688 \mu \mathrm{m} \cdot \pi / 18=2.56 \mu \mathrm{m}$.
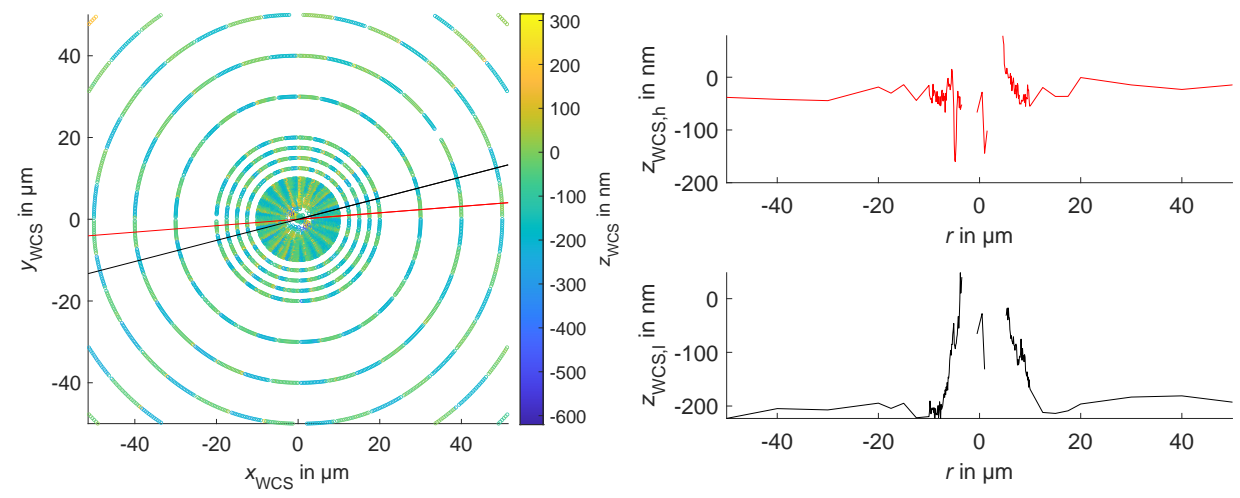

Figure 6. One line through the middle of a groove (black) and one through the middle of the adjacent top level (red). 


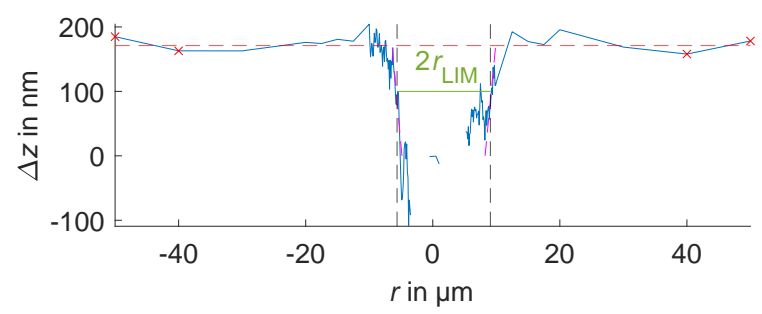

Figure 7. $\Delta z$ over $r$ and the calculation of $2 r_{\text {LIM }}$.

\subsection{Measurement and Evaluation according to the NPL Good Practice Guide}

The main intention of the NPL Good Practice Guide is to achieve a far shorter measurement time when only two line scans are conducted compared to the complete measurement of the Siemens star. Therefore, a line scan has been conducted through the middle of a groove and through the middle of the adjacent top level with a scanning length of $50 \mu \mathrm{m}$ and a point distance of $5 \mathrm{~nm}$ each and the angle again determined using $\phi$ of the Fourier series of the radial measurement at $r=60 \mu \mathrm{m}$. Furthermore, to evaluate the effect of a misidentified target centre, several parallel line scans were conducted with a distance of $50 \mathrm{~nm}$ (in sum, 31 line scans both on the groove and on the adjacent top level). In Figure 8, the line scans on the top adjacent to the groove are shown. Also shown is the line scan going through the previously determined centre of the Siemens star (dashed black line). As is perceptible, this line scan does not go through the actual centre of the Siemens star. To determine the line scan going the closest through the actual centre, for each scan line , $D_{\text {LIM }}$ is calculated using $V_{\text {in }}$ instead of $z_{\mathrm{WCS}}$, as $V_{\text {in }}$ is not deteriorated by edge effects. The line scan with the smallest $D_{\text {LIM }}$ is the one going the closest through the actual centre (dashed red line). The distance between the dashed red line and the dashed black line is $250 \mathrm{~nm}$.

The novel centre point of the Siemens star, $C_{n}$, is determined as intersection point of the line scan with the smallest $D_{\text {LIM }}$ in the groove and the line scan with the smallest $D_{\text {LIM }}$ on the adjacent top level. For each line scan, $r$ is calculated as signed distance to $C_{\mathrm{n}}$ and $\Delta z$ is calculated with the nearest-neighbour point. As the point distance is by far smaller than $D_{\text {LIM }}$, the slight mismatch of a few $\mathrm{nm}$ is negligible. The determination of $D_{\text {LIM }}$ necessitates the evaluation of the topographic data $z_{\text {WCS }}$; therefore, in Figure 9 , left, $\Delta z$ over $r$ is shown. It can be seen that there is noise on the data. In contrast, the Fourier series approximation for the radial evaluation (cf. Section 4) already incorporates a low-pass filter to remove the noise. Measurement noise is a separate characteristic of an optical instrument according to ISO 25178-600 [37]. Thus, it is removed with a mean value filter of length 100 ( $\widehat{=} 500 \mathrm{~nm}$ ) for the line scans. Although the effect of this filter on the determined $D_{\text {LIM }}$ is rather small, as there are many data points contributing to the calculation of $a_{0}$ and the polynomial, it certainly facilitates choosing the right data points to calculate the polynomial. It is noteworthy that filtering is also applied for the evaluation of chirp measurement standards [81]. On the right side of the figure, the filtered data and the evaluation of $2 r_{\text {LIM }}$, which is $12.698 \mu \mathrm{m}$, are shown. Therefore, $D_{\text {LIM }}=2.22 \mu \mathrm{m}$.
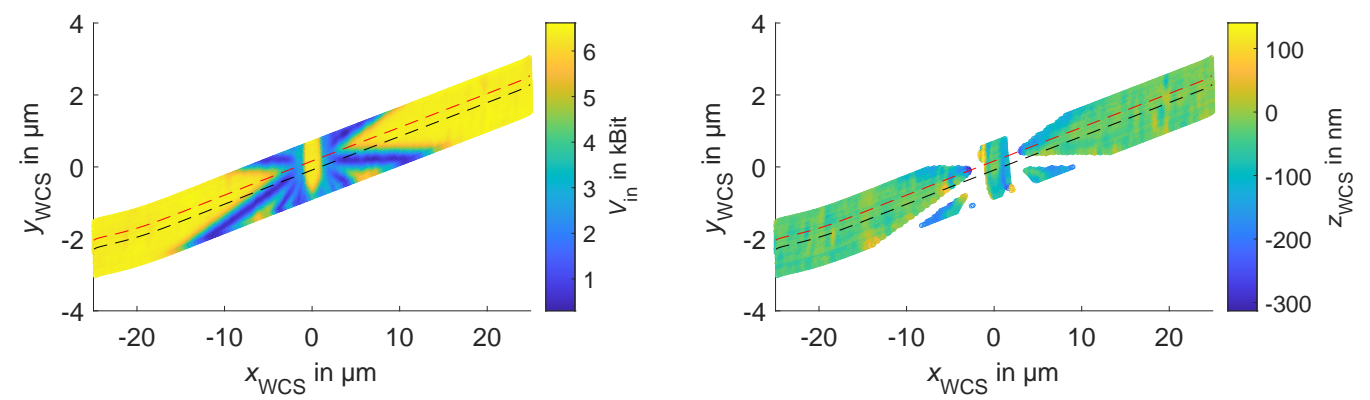

Figure 8. $V_{\text {in }}$ and $z_{\text {WCS }}$ for the line scans on the top adjacent to the groove. Shown in black is the line scan going through the previously determined centre of the Siemens star, and shown in red is the line scan going through $C_{n}$. 

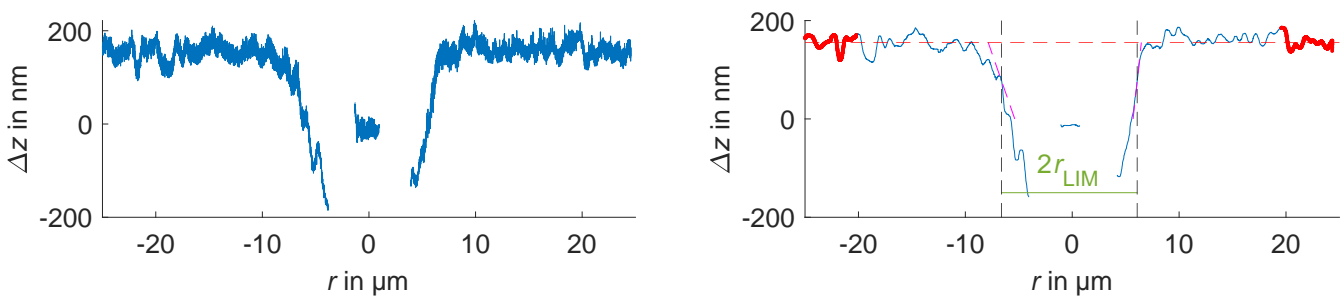

Figure 9. (Left): $\Delta z$ calculated with the line scans going through $C_{\mathrm{n}}$ over $r$. (Right): $\Delta z$ filtered and calculation of $2 r_{\text {LIM }}$.

\subsection{Effect of a Misidentified Target Centre}

To quantify the effect of a misidentified target centre, $D_{\text {LIM }}$ was calculated also with the adjacent lines of the ones going the closest through $C_{n}$. The results are shown in Table 1. In Table 2, the corresponding distance of the intersection point of the two scan lines to $C_{n}$ is shown. Due to the sharp angle between the two scan lines $\left(10^{\circ}\right)$, a slight offset of one scan line results in a mismatch of the centre amplified by the factor of $1 / \sin \left(10^{\circ}\right) \approx 5.76$. Therefore, although the offsets are only in a range of $\pm 100 \mathrm{~nm}$, the distance between the intersection point of the two lines and $C_{\mathrm{n}}$ reaches more then one $\mu \mathrm{m}$ for a disadvantageous combination of the offsets, and the difference between the maximum $(2.64 \mu \mathrm{m})$ and minimum $(1.94 \mu \mathrm{m})$ value of $D_{\text {LIM }}$ is therefore already $0.70 \mu \mathrm{m}$. Taking the $2.22 \mu \mathrm{m}$ as reference, the deviations are 19\% (maximum value) and $13 \%$ (minimum value). Remarkably, a misidentified target centre does not necessarily result in an overestimation of $D_{\mathrm{LIM}}$, but lower values might also be obtained. This is probably a result of the well-known edge effects observable with many optical systems. These findings strongly underline the necessity to modify the NPL Good Practice Guide to include a thorough determination of the Siemens star's centre before the actual determination of $D_{\text {LIM }}$.

Table 1. $D_{\mathrm{LIM}}$ in $\mu \mathrm{m}$ calculated with the lines having an offset to the ones going the closest through $C_{n}$.

\begin{tabular}{lc|ccccc}
\hline & & \multicolumn{5}{|c}{ offset 1 in $\mathbf{~ m}$} \\
& & $-\mathbf{0 . 1 0 0}$ & $-\mathbf{0 . 0 5 0}$ & $\mathbf{0 . 0 0 0}$ & $\mathbf{0 . 0 5 0}$ & $\mathbf{0 . 1 0 0}$ \\
\hline & $-\mathbf{0 . 1 0 0}$ & 2.18 & 2.20 & 2.24 & 2.39 & 2.63 \\
offset 2 in $\mathbf{\mu m}$ & $\mathbf{- 0 . 0 5 0}$ & 2.15 & 2.18 & 2.31 & 2.39 & 2.64 \\
& $\mathbf{0 . 0 0 0}$ & 2.15 & 2.18 & 2.22 & 2.38 & 2.62 \\
& $\mathbf{0 . 0 5 0}$ & 2.03 & 2.13 & 2.18 & 2.20 & 2.57 \\
& $\mathbf{0 . 1 0 0}$ & 1.94 & 2.00 & 2.14 & 2.16 & 2.37 \\
\hline
\end{tabular}

Table 2. Distance to $C_{n}$ in $\mu \mathrm{m}$.

\begin{tabular}{cc|ccccc}
\hline & & \multicolumn{5}{|c}{ offset 1 in $\boldsymbol{\mu m}$} \\
& & $-\mathbf{0 . 1 0 0}$ & $-\mathbf{0 . 0 5 0}$ & $\mathbf{0 . 0 0 0}$ & $\mathbf{0 . 0 5 0}$ & $\mathbf{0 . 1 0 0}$ \\
\hline \multirow{4}{*}{ offset 2 in $\mathbf{\mu m}$} & $-\mathbf{0 . 1 0 0}$ & 0.101 & 0.293 & 0.569 & 0.851 & 1.135 \\
& $-\mathbf{0 . 0 5 0}$ & 0.294 & 0.050 & 0.285 & 0.567 & 0.851 \\
& $\mathbf{0 . 0 0 0}$ & 0.570 & 0.285 & 0 & 0.285 & 0.570 \\
& $\mathbf{0 . 0 5 0}$ & 0.852 & 0.567 & 0.285 & 0.05 & 0.294 \\
& $\mathbf{0 . 1 0 0}$ & 1.135 & 0.851 & 0.569 & 0.293 & 0.101 \\
\hline
\end{tabular}

\subsection{Modified Good Practice Guide}

Based on the presented findings, we propose the following summarized procedure to determine the $D_{\text {LIM }}$ of an optical point sensor using a Siemens star:

1. Roughly determine the centre of the Siemens star.

2. Conduct a radial measurement on a radius where the structures are well resolvable.

3. Calculate the phase of the structures by a Fourier series approximation of this radial measurement. 
4. Conduct several parallel line scans with a small offset in the direction of the phase of the structures in a groove and on an adjacent top level.

5. Determine the line scans going through the centre of the Siemens star by finding, for the scans both in a groove and on an adjacent top level, the one with the smallest $D_{\text {LIM }}$ when evaluating the unprocessed raw signal, for instance, of the photodetector, not the topographic data.

6. Calculate $D_{\text {LIM }}$ with the topographic data of the two line scans that go through the centre of the Siemens star. An appropriate low-pass filter should be applied to reduce the noise level of the data.

\section{Summary}

In this article, the determination of $D_{\text {LIM }}$ of an optical point sensor, or a confocal sensor to be more specific, with a type ASG material measure, also called a (topographic) Siemens star, has been shown. It has been determined following the radial approach, as proposed by ISO 25178-70 [48] and following the NPL Good Practice Guide [53]. For the latter, only two lines taken at a groove and the adjacent top level are measured and evaluated, leading to a much faster evaluation of $D_{\text {LIM }}$. Nonetheless, as has been shown, only slight lateral errors of the scan lines lead to significant errors of the intersection point of the scan lines and the actual centre of the Siemens star and therefore of the determined $D_{\text {LIM }}$. Errors of up to $19 \%$ of the determined $D_{\text {LIM }}$ have been shown for lateral errors of the scan lines of $\pm 100 \mathrm{~nm}$. Remarkably, a misidentified target centre does not necessarily result in an overestimation of $D_{\mathrm{LIM}}$, but lower values might also be obtained. Therefore, a modified Good Practice Guide has been proposed to determine $D_{\text {LIM }}$ more accurately. It includes a thorough determination of the centre of the Siemens star. While the measurement and evaluation effort is increased slightly compared to the NPL Good Practice Guide, it is still much faster than a complete radial measurement and evaluation.

\section{Conclusions}

The application of the presented procedure necessitates access to the raw data of the measuring instrument to accurately determine the centre of the Siemens star. These data are seldom accessible in practice, but there are still some general conclusions that might be drawn from the presented findings. The determination of the seven metrological characteristics of ISO 25178-600, including $D_{\mathrm{LIM}}$, might be used to estimate the measurement uncertainty for a surface topography measurement in a simple manner following the metrological characteristics framework [36]. This framework assumes to always overestimate the measurement uncertainty by deliberately counting some influence quantities more than once. Nevertheless, as has been shown within this publication, an inaccurate positioner might lead to a significant underestimation of $D_{\mathrm{LIM}}$, which in turn might lead to an underestimation of the uncertainty estimated following the metrological characteristics framework. Thus, an accurate lateral positioner is a prerequisite for the determination of $D_{\text {LIM }}$ with a Siemens star and a point sensor. If the lateral positioner has larger errors, it is preferable to determine $D_{\text {LIM }}$ with other measures such chirped calibration standards or rectangular gratings. On the downside, it might also be possible to increase the angle between both scan lines and therefore to not measure the adjacent but a slightly further top level. This reduces the effect an inaccurate line scan has on the discrepancy of the intersection point between both scan lines and the actual centre point of the Siemens star.

Author Contributions: Conceptualization, J.S. and T.H.; methodology, J.S., A.C.G., and T.H.; software, J.S.; validation, J.S.; formal analysis, J.S. and A.C.G.; investigation, J.S. and A.C.G.; resources, T.H.; data curation, J.S.; writing-original draft preparation, J.S.; writing-review and editing, A.C.G. and T.H.; visualization, J.S. and A.C.G.; supervision, T.H.; project administration, T.H.; funding acquisition, T.H. All authors have read and agreed to the published version of the manuscript. 
Funding: This project 20IND07 TracOptic has received funding from the EMPIR programme cofinanced by the Participating States and from the European Union's Horizon 2020 research and innovation programme.

Institutional Review Board Statement: Not applicable.

Informed Consent Statement: Not applicable.

Data Availability Statement: Data underlying the results presented in this paper are not publicly available at this time but may be obtained from the authors upon reasonable request.

Acknowledgments: The authors thank the anonymous reviewers whose comments helped to improve and clarify this paper.

Conflicts of Interest: The authors declare no conflict of interest.

\section{References}

1. Bruzzone, A.A.G.; Costa, H.L.; Lonardo, P.M.; Lucca, D.A. Advances in engineered surfaces for functional performance. CIRP Ann. 2008, 57, 750-769. [CrossRef]

2. Zhang, S.; Zhou, Y.; Zhang, H.; Xiong, Z.; To, S. Advances in ultra-precision machining of micro-structured functional surfaces and their typical applications. Int. J. Mach. Tools Manuf. 2019, 142, 16-41. [CrossRef]

3. Blondiaux, N.; Diserens, M.; Chauvy, P.F.; Oudot, B.; Pugin, R. Manufacturing of hierarchically structured surfaces for decorative applications. In Proceedings of the Euspen's 21st International Conference \& Exhibition, Copenhagen, Denmark, 7-10 June 2021; pp. 119-120.

4. Leach, R. Introduction to Surface Texture Measurement. In Optical Measurement of Surface Topography, 1st ed.; Leach, R., Ed.; Springer: Berlin/Heidelberg, Germany, 2011; Chapter 1, pp. 1-15.

5. Jiang, X.J.; Whitehouse, D.J. Technological shifts in surface metrology. CIRP Ann. 2012, 61, 815-836. [CrossRef]

6. Leach, R.; Ferrucci, M.; Haitjema, H. Dimensional Metrology. In CIRP Encyclopedia of Production Engineering; Springer: Berlin/Heidelberg, Germany, 2019; pp. 1-11.

7. Joint Committee for Guides in Metrology. JCGM 100:2008. Evaluation of Measurement Data-Guide to the Expression of Uncertainty in Measurement. 2008. Available online: https://www.bipm.org/documents/20126/2071204/JCGM_100_2008_E. pdf/cb0ef43f-baa5-11cf-3f85-4dcd86f77bd6 (accessed on 1 October 2021).

8. Haitjema, H. Measurement Uncertainty. In CIRP Encyclopedia of Production Engineering; Laperrière, L., Reinhart, G., Eds.; Springer: Berlin/Heidelberg, Germany, 2014; pp. 852-857.

9. Whitehouse, D.J. Comparison Between Stylus and Optical Methods for Measuring Surfaces. CIRP Ann. 1988, 37, 649-653. [CrossRef]

10. Weckenmann, A.; Estler, T.; Peggs, G.; McMurtry, D. Probing Systems in Dimensional Metrology. CIRP Ann. 2004, 53, 657-684. [CrossRef]

11. Leach, R.K.; Giusca, C.L.; Naoi, K. Development and characterization of a new instrument for the traceable measurement of areal surface texture. Meas. Sci. Technol. 2009, 20, 125102. [CrossRef]

12. Thomsen-Schmidt, P. Characterization of a traceable profiler instrument for areal roughness measurement. Meas. Sci. Technol. 2011, 22, 094019. [CrossRef]

13. Nouira, H.; Salgado, J.A.; El-Hayek, N.; Ducourtieux, S.; Delvallée, A.; Anwer, N. Setup of a high-precision profilometer and comparison of tactile and optical measurements of standards. Meas. Sci. Technol. 2014, 25, 044016. [CrossRef]

14. Binnig, G.; Quate, C.F.; Gerber, C. Atomic Force Microscope. Phys. Rev. Lett. 1986, 56, 930-933. [CrossRef] [PubMed]

15. Meyer, G.; Amer, N.M. Optical-beam-deflection atomic force microscopy: The $\mathrm{NaCl}$ (001) surface. Appl. Phys. Lett. 1990, 56, 2100-2101. [CrossRef]

16. Giessibl, F.J.; Gerber, C.; Binnig, G. A low-temperature atomic force/scanning tunneling microscope for ultrahigh vacuum. J. Vac. Sci. Technol. B 1990, 9, 984-988. [CrossRef]

17. Danzebrink, H.U.; Pohlenz, F.; Dai, G.; Dal Savio, C. Metrological Scanning Probe Microscope-Instruments for Dimensional Nanometrology. In Nanoscale Calibration Standards and Methods: Dimensional and Related Measurements in the Micro-and Nanometer Range, 1st ed.; Wilkening, G., Koenders, L., Eds.; Wiley-VCH: Hoboken, NJ, USA, 2005; pp. 3-21.

18. Lonardo, P.M.; Lucca, D.A.; De Chiffre, L. Emerging Trends in Surface Metrology. CIRP Ann. 2002, 51, 701-723. [CrossRef]

19. Schwenke, H.; Neuschaefer-Rube, U.; Pfeifer, T.; Kunzmann, H. Optical Methods for Dimensional Metrology in Production Engineering. CIRP Ann. 2002, 51, 685-699. [CrossRef]

20. Gao, W.; Haitjema, H.; Fang, F.Z.; Leach, R.K.; Cheung, C.F.; Savio, E.; Linares, J.M. On-machine and in-process surface metrology for precision manufacturing. CIRP Ann. 2019, 68, 843-866. [CrossRef]

21. Schmitt, R.; Damm, B. Maschinenintegrierte Messtechnik. In Koordinatenmesstechnik—Flexible Strategien für Funktions- und Fertigungsgerechtes Prüfen, 2nd ed.; Weckenmann, A., Ed.; Carl Hanser: München, Germany; Wien, Austria, 2012; Chapter 5.8, pp. 244-252.

22. Whitehouse, D.J. Handbook of Surface and Nanometrology, 2nd ed.; CRC Press: Boca Raton, FL, USA, 2011. 
23. Hillmann, W.; Kunzmann, H. Surface Profiles Obtained by Means of Optical Methods-Are They True Representations of the Real Surface? CIRP Ann. 1990, 39, 581-583. [CrossRef]

24. Haitjema, H. International comparison of depth-setting standards. Metrologia 1997, 34, 161-167. [CrossRef]

25. Leach, R.; Hart, A. A Comparison of Stylus and Optical Methods for Measuring 2D Surface Texture; NPL Report CBTLM 15; National Physical Laboratory: Teddington, UK, 2002.

26. Rhee, H.G.; Vorburger, T.V.; Lee, J.W.; Fu, J. Discrepancies between roughness measurements obtained with phase-shifting and white-light interferometry. Appl. Opt. 2005, 44, 5919-5927. [CrossRef]

27. Ottevaere, H.; Schwider, J.; Kacperski, J.; Steinbock, L.; Weible, K.; Kujawinska, M.; Thienpont, H. Benchmarking instrumentation tools for the characterization of microlenses within the EC Network of Excellence on Micro-Optics (NEMO). Proc. SPIE 2008, 6995, 69950J.

28. McCarthy, M.B.; Brown, S.B.; Evenden, A.; Robinson, A.D. NPL freeform artefact for verification of non-contact measuring systems. Proc. SPIE 2011, 7864, 78640K.

29. Tosello, G.; Haitjema, H.; Leach, R.K.; Quagliotti, D.; Gasparin, S.; Hansen, H.N. An international comparison of surface texture parameters quantification on polymer artefacts using optical instruments. CIRP Ann. 2016, 65, 529-532. [CrossRef]

30. Launhardt, M.; Wörz, A.; Loderer, A.; Laumer, T.; Drummer, D.; Hausotte, T.; Schmidt, M. Detecting surface roughness on SLS parts with various measuring techniques. Polym. Test. 2016, 53, 217-226. [CrossRef]

31. Heinl, M.; Greiner, S.; Wudy, K.; Pobel, C.; Rasch, M.; Huber, F.; Papke, T.; Merklein, M.; Schmidt, M.; Körner, C.; et al. Measuring procedures for surface evaluation of additively manufactured powder bed-based polymer and metal parts. Meas. Sci. Technol. 2020, 31, 095202. [CrossRef]

32. DIN EN ISO 14406:2010. Geometrical Product Specification (GPS)—Extraction (ISO 14406:2010); Beuth Verlag: Berlin, Germany, 2010.

33. Leach, R.; Haitjema, H. Bandwidth characteristics and comparisons of surface texture measuring instruments. Meas. Sci. Technol. 2010, 21, 032001. [CrossRef]

34. Song, J.; Vorburger, T.; Renegar, T.; Rhee, H.; Zheng, A.; Ma, L.; Libert, J.; Ballou, S.; Bachrach, B.; Bogart, K. Correlation of topography measurements of NIST SRM 2460 standard bullets by four techniques. Meas. Sci. Technol. 2006, 17, 500-503. [CrossRef]

35. Badami, V.G.; Liesener, J.; Evans, C.J.; de Groot, P. Evaluation of the measurement performance of a coherence scanning microscope using roughness specimens. Proc. ASPE 2011, 52, 23-26.

36. Leach, R.; Haitjema, H.; Su, R.; Thompson, A. Metrological characteristics for the calibration of surface topography measuring instruments: A review. Meas. Sci. Technol. 2021, 32, 032001. [CrossRef]

37. DIN EN ISO 25178-600:2019. Geometrical Product Specification (GPS)—Surface Texture: Areal_Part 600: Metrological Characteristics for Areal-Topography Measuring Methods (ISO 25178-600:2019); Beuth Verlag: Berlin, Germany, 2019.

38. Lord Rayleigh, F.R.S. Investigations in Optics, with special reference to the Spectroscope. Lond. Edinb. Philos. Mag. J. Sci. 1879, 8, 261-274. [CrossRef]

39. Sparrow, C.M. On Spectroscopic Resolving Power. Astrophys. J. 1916, 44, 76-86. [CrossRef]

40. Leach, R. Some Common Terms and Definitions. In Optical Measurement of Surface Topography, 1st ed.; Leach, R., Ed.; Springer: Berlin/Heidelberg, Germany, 2011; Chapter 2, pp. 15-22.

41. de Groot, P.; de Lega, X.C.; Sykora, D.; Deck, L. The Meaning and Measure of Lateral Resolution for Surface Profiling Interferometers. Opt. Photonics News 2012, 23, 10-13.

42. Krüger-Sehm, R.; Bakucz, P.; Jung, L.; Wilhelms, H. Chirp-Kalibriernormale für Oberflächenmessgeräte. Tech. Mess. 2007, 74, 572-576. [CrossRef]

43. Fujii, A.; Suzuki, H.; Yanagi, K. Development of measurement standards for verifying functional performance of surface texture measuring instruments. J. Phys. Conf. Ser. 2011, 311, 012009. [CrossRef]

44. Wohlgemuth, F.; Fleßner, M.; Hausotte, T. Determination of Metrological Structural Resolution using an Aperiodic Spatial Frequency Standard. In Proceedings of the International Symposium on Digital Industrial Radiology and Computed Tomography, Fürth, Germany, 2- 4 July 2019; pp. 1-10.

45. Illemann, J. Traceable measurement of the instrument transfer function in dXCT. In Proceedings of the 10th Conference on Industrial Computed Tomography, Wels, Austria, 4-7 February 2020.

46. Krüger-Sehm, R.; Frühauf, J.; Dziomba, T. Determination of the short wavelength cutoff of interferential and confocal microscopes. Wear 2008, 264, 439-443. [CrossRef]

47. Pehnelt, S.; Osten, W.; Seewig, J. Vergleichende Untersuchung optischer Oberflächenmessgeräte mit einem Chirp-Kalibriernormal. Tech. Mess. 2011, 78, 457-462. [CrossRef]

48. DIN EN ISO 25178-70:2014. Geometrical Product Specification (GPS)—Surface Texture: Areal—Part 70: Material Measures (ISO 25178-70:2014); Beuth Verlag: Berlin, Germany, 2014.

49. Weckenmann, A.; Tan, O.; Hoffmann, J.; Sun, Z. Practice-oriented evaluation of lateral resolution for micro- and nanometre measurement techniques. Meas. Sci. Technol. 2009, 20, 065103. [CrossRef] 
50. Sebaihi, N.; Pétry, J.; Koops, R.; Valtr, M.; Klapetek, P.; Dai, G.; Hausotte, T.; Klöpzig, U.; Wu, Y.; Korpelainen, V. Good Practice Guide for Dimensional Metrology at the Nanometer Scale in General and for Using the Developed Reference Standards and Methodologies in Particular; Technical Report, 15SIB09 3DNano-Traceable Three-Dimensional Nanometrology. 2019. Available online: https://www.ptb.de/emrp/index.php?eID=tx_nawsecuredl\&u=0\&file=fileadmin /documents $/ 3 \mathrm{dnano} / \mathrm{memberupload/}$ documents/Work\%20Packages/WP4/D7_Good_practice_guide_Final_website.pdf\&t=1640860564\&hash=fd3e8085feab2a7b9 3dfa9d0c395064a89740ae9 (accessed on 1 October 2021).

51. Yang, R.; Li, F.; Hong, B.; Hu, Z. Measurement Error of Spatial Frequency Response Based on sinusoidal Siemens Star. Proc. SPIE 2020, 11567, 115673V.

52. Giusca, C.L.; Leach, R.K. Calibration of the scales of areal surface topography measuring instruments: Part 3. Resolution. Meas. Sci. Technol. 2013, 24, 105010. [CrossRef]

53. Giusca, C.L.; Leach, R.K. Measurement Good Practice Guide No. 128-Calibration of the Metrological Characteristics of Imaging Confocal Microscopes (ICMs); Techreport; National Physical Laboratory: Teddington, UK, 2012.

54. Birch, G.C.; Griffin, J.C. Sinusoidal Siemens star spatial frequency response measurement errors due to misidentified target centers. Opt. Eng. 2015, 54, 074104. [CrossRef]

55. Eifler, M.; Ströer, F.; Hering, J.; von Freymann, G.; Seewig, J. User-oriented evaluation of the metrological characteristics of areal surface topography measuring instruments. Proc. SPIE 2019, 11056, 110560Y.

56. Minsky, M. Microscopy Apparatus. U.S. Patent 3,013,467, 19 December 1961.

57. Sheppard, C.J.R.; Choudhury, A. Image Formation in the Scanning Microscope. Opt. Acta 1977, 24, 1051-1073. [CrossRef]

58. Brakenhoff, G.J.; Blom, P.; Barends, P. Confocal scanning light microscopy with high aperture immersion lenses. J. Microsc. 1979, 117, 219-232. [CrossRef]

59. White, J.G.; Amos, W.B.; Fordham, M. An evaluation of confocal versus conventional imaging of biological structures by fluorescence light microscopy. J. Cell Biol. 1987, 105, 41-48. [CrossRef]

60. Hamilton, D.K.; Wilson, T. Surface profile measurement using the confocal microscope. J. Appl. Phys. 1982, 53, 5320-5322. [CrossRef]

61. DIN EN ISO 25178-607:2019. Geometrical Product Specification (GPS)—Surface Texture: Areal_Part 607: Nominal Characteristics of Non-Contact (Confocal Microscopy) Instruments (ISO 25178-607:2019); Beuth Verlag: Berlin, Germany, 2019.

62. Lukosz, W. Optical Systems with Resolving Powers Exceeding the Classical Limit. J. Opt. Soc. Am. 1966, 56, 1463-1472. [CrossRef]

63. Artigas, R. Imaging Confocal Microscopy. In Optical Measurement of Surface Topography, 1st ed.; Leach, R., Ed.; Springer: Berlin/Heidelberg, Germany, 2011; Chapter 11, pp. 237-286.

64. Petráň, M.; Hadravský, M.; Egger, M.D.; Galambos, R. Tandem-Scanning Reflected-Light Microscope. J. Opt. Soc. Am. 1968, 58, 661-664. [CrossRef]

65. Weber, K. Vorrichtung zur optischen Abtastung mikroskopischer Objekte. Deutsches Patentamt Offenlegungsschrift 1472293 , 4 December 1969.

66. Wilke, V. Optical Scanning Microscopy-The Laser Scan Microscope. Scanning 1985, 7, 88-96. [CrossRef]

67. Hausotte, T.; Gröschl, A.; Schaude, J. High-speed focal-distance-modulated fiber-coupled confocal sensor for coordinate measuring systems. Appl. Opt. 2018, 57, 3907-3914. [CrossRef] [PubMed]

68. Schaude, J.; Gröschl, A.C.; Hausotte, T. Stitched open-loop measurements with a focal-distance-modulated confocal sensor. Tech Mess. 2021, 88, 544-555. [CrossRef]

69. Gu, M.; Sheppard, C.J.R.; Gan, X. Image formation in a fiber-optical confocal scanning microscope. J. Opt. Soc. Am. A 1991, 8, 1755-1761. [CrossRef]

70. Gröschl, A. Hochfrequent fokusabstandsmodulierte Konfokalsensoren für die Nanokoordinatenmesstechnik. Ph.D. Thesis, FAU Erlangen-Nürnberg, Erlangen, Germany, 2021.

71. Hausotte, T.; Percle, B.; Jäger, G. Advanced three-dimensional scan methods in the nanopositioning and nanomeasuring machine. Meas. Sci. Technol. 2009, 20, 084004. [CrossRef]

72. Hausotte, T. Interferometric measuring systems of nanopositioning and nanomeasuring machines. Proc. SPIE 2018, 10678, 106780Q.

73. Gröschl, A.C.; Schaude, J.; Hausotte, T. Evaluation und Korrektur thermischer Driften eines hochfrequent fokusabstandsmodulierten, fasergekoppelten konfokalen Punktsensors. Tech. Mess. 2019, 86, 117-121. [CrossRef]

74. Abbe, E. Meßapparate für Physiker. Zeitschrift für Instrumentenkunde 1890, 10, 446-448.

75. Leach, R.K.; Giusca, C.L.; Rubert, P. A single set of material measures for the calibration of areal surface topography measuring instruments: The NPL Areal Bento Box. Proc. Met. Props. 2013, 23, 406-413.

76. Wilson, T.; Sheppard, C. Theory and Practice of Scanning Optical Microscopy, 1st ed.; Academic Press: London, UK, 1984.

77. Aguilar, J.F.; Méndez, E.R. On the Limitations of the Confocal Scanning Optical Microscope as a Profilometer. J. Mod. Opt. 1995, 42, 1785-1794. [CrossRef]

78. Harasaki, A.; Wyant, J.C. Fringe modulation skewing effect in white-light vertical scanning interferometry. Appl. Opt. 2000, 39, 2101-2106. [CrossRef]

79. Langholz, N.; Seewig, J.; Reithmeier, E. Robust surface fitting-Using weights based on a priori knowledge about the measurement process. Wear 2009, 266, 515-517. [CrossRef] 
80. Gröschl, A.C.; Schaude, J.; Hausotte, T. Evaluation of the optical performance of a novel high-speed focal-distance-modulated fibre-coupled confocal sensor. Proc. SPIE 2019, 11056, 110560N.

81. Seewig, J.; Eifler, M.; Wiora, G. Unambiguous evaluation of a chirp measurement standard. Surf. Topogr. Metrol. Prop. 2014, 2, 045003. [CrossRef] 